\title{
The Preliminary Geology of the DO-18 Kimberlite, Lac de Gras Kimberlite Province, Canada
}

\author{
M. Harder ${ }^{1}$, C.M. Hetman ${ }^{1}$, M.C. Baumgartner ${ }^{1}$, and J. Pell ${ }^{2}$ \\ ${ }^{1}$ Mineral Services Canada Inc., North Vancouver, Canada \\ ${ }^{2}$ Peregrine Diamonds Ltd., Vancouver, Canada
}

\section{Introduction}

The DO-18 and DO-27 kimberlites were discovered in 1993 in the Lac de Gras kimberlite province (Figure 1; Doyle et al., 1999). The DO-18 kimberlite is located approximately $400 \mathrm{~m}$ north of DO-27 and is a separate, distinct body (Harder et al., 2008). The DO-18 kimberlite was emplaced into Archean granitoids of the Slave Province and an overlying veneer of late Cretaceous to Eocene mudstones (Doyle et al., 1999). The pipe has a surface expression of approximately 4 hectares and is characterised by inward-tapering, steep-sided pipe walls. Recent evaluation of DO-18 by Peregrine Diamonds Limited has included core drilling and processing of the kimberlite for microdiamonds and indicator mineral abundance and composition studies.

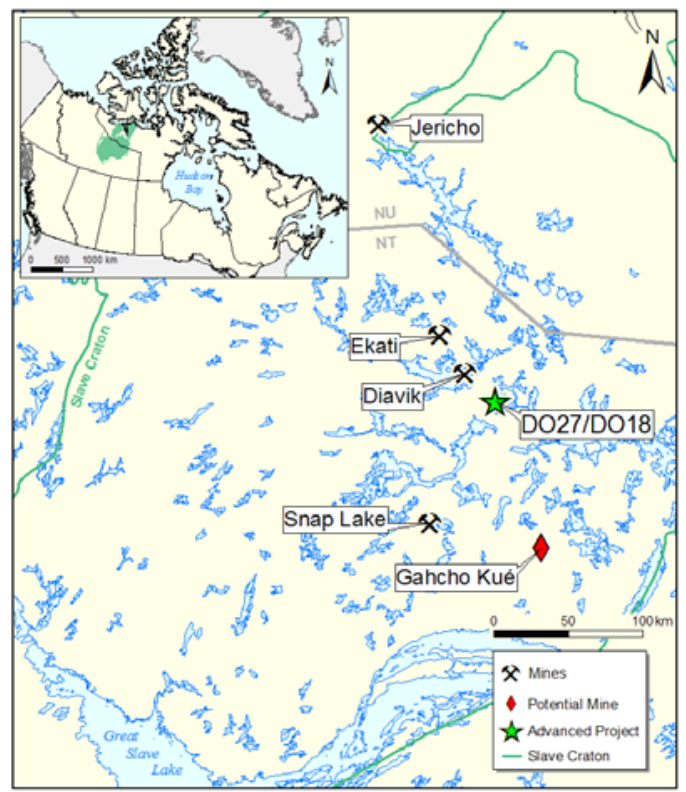

Figure 1: The DO-18 and DO-27 kimberlites are located in the Lac de Gras kimberlite province, Slave structural province, Northwest Territories, Canada.

\section{DO-18 Geology}

Core logging and preliminary petrography has revealed the DO-18 body to be comprised of two main kimberlite domains. The largest of these is located primarily in the northern and central part of the body and is referred to as KIMB-1 (Figure 2). KIMB-1 is characterised by a generally high proportion (> $25 \%$ ) of accessory country-rock granite and minor amounts of mud-rich resedimented volcaniclastic kimberlite (RVK). The kimberlite is green/grey in colour, clastsupported, well-packed and poorly sorted, comprising approximately $30 \%$ (locally up to $40 \%$ ), fine to medium-grained, serpentinized olivine (Figure 3). The inter-clast matrix consists of serpentine and kimberlitic ash. Juvenile clasts comprise $<10 \%$ of the kimberlite and two possible varieties are present: an olivine phenocryst-rich clast type and a less olivine phenocryst-rich, phlogopite-bearing clast type. Structurally this domain is massive to diffusely bedded, with local grain-flow beds comprising slightly coarser olivines and mud clasts. Large-scale variations with respect to xenolith concentration and size occur throughout KIMB-1, with domains characterised by a high proportion of large $(>10 \mathrm{~cm}$ ) xenoliths occurring at depth in the centre of the pipe and locally along the pipe margins. KIMB-1 is texturally classified as volcaniclastic kimberlite (VK), and based on the features described above was likely deposited by primary pyroclastic processes. It can therefore be further classified as pyroclastic kimberlite (PK).

The second domain, referred to as KIMB-2 (Figure 2), is located primarily in the southern part of the body. KIMB-2 is a variably, but generally juvenile-rich, locally bedded, grey/brown kimberlite characterised by an inter-clast matrix dominated by mud and kimberlitic ash (Figure 2). Accretionary lapilli comprising concentric rims of mud plus kimberlitic ash are locally present. Although this domain contains a generally lower proportion of accessory granite ( $>1 \mathrm{~cm}$ in size), locally KIMB-2 comprises up to $40 \%$ granitic xenocrysts $(<1 \mathrm{~cm})$. Distinct bedding with respect to granitic xenocrysts, olivine grain size, and mud clasts is observed. Glauconite-bearing mud clasts are distinctive of KIMB-2, although these are rarely observed in KIMB-1 as well. Texturally, this kimberlite is more variable than KIMB-1, ranging from clast-supported and well-packed (particularly in granite xenocryst-rich areas) to matrix-supported by mud and kimberlitic ash (Figure 4). Fine to medium-grained, serpentinized olivine comprises approximately 25-30\% of the kimberlite; however, the proportion of olivine varies from 15 to $40 \%$, which in part defines the more distinct bedding observed in this domain. Juvenile clasts are present but comprise $<5 \%$ of the kimberlite. The same varieties of juvenile clasts are observed in both KIMB-1 and KIMB-2 domains, suggesting they derive from the same kimberlite phases, and therefore the mantle component is likely the same in both units. KIMB-2 is texturally classified as RVK. The differences in kimberlite character between KIMB-1 and KIMB-2 are likely the result of varied primary

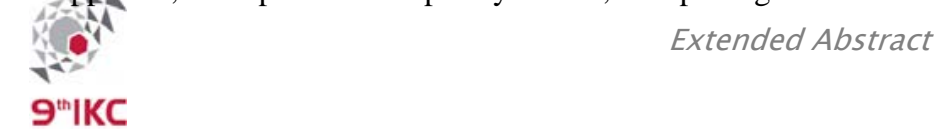


volcanic and secondary resedimentation processes, rather than separate kimberlite eruptions/phases.

\section{Surficial Mudstones and Palynology Dating}

The mudstones present at surface during emplacement of the DO-18 kimberlite were incorporated into the pipe infill as both moderately to poorly consolidated clasts and as unconsolidated material present in the inter-clast matrix. The mudstones were deposited during the northernmost stand of the Western Interior Seaway and are now preserved only as part of the kimberlite pipe infill, the remainder having been removed by erosion subsequent to kimberlite volcanism. Numerous varieties of mud are observed in the kimberlite, ranging in colour from dark brown to silvery grey and in competency from unconsolidated matrix material to soft and deformed clasts, and hard, distinct clasts. Palynology dating of these sediments constrains the age of the DO-18 kimberlite to between 45 and 75 Ma (Sweet et al., 1998). The DO-18 kimberlite is likely Late Cretaceous to Paleocene in age based on the youngest palynomorphs observed. Both marine and non-marine palynomorphs and organic debris indicate a dominantly terrestrial environment into which the DO-18 kimberlite was emplaced, but with a strong marine influence evident in the sediments.

\section{Mantle Sample}

Mineral composition data for DO-18 indicate the kimberlite sampled the lithospheric mantle well within the diamond stability field. This mantle material equilibrated on a cratonic geotherm of $37 \mathrm{~mW} / \mathrm{m}^{2}$, which is consistent with other kimberlites from the Lac de Gras province. The indicator mineral suite is dominated by peridotitic garnets and $\mathrm{Cr}$-diopside, with lesser chromite and trace amounts of eclogitic, megacrystic, and pyroxenitic garnet. No mantlederived ilmenite is present. Indicator mineral abundances are generally slightly higher in KIMB-1 than in the KIMB-2 domain.

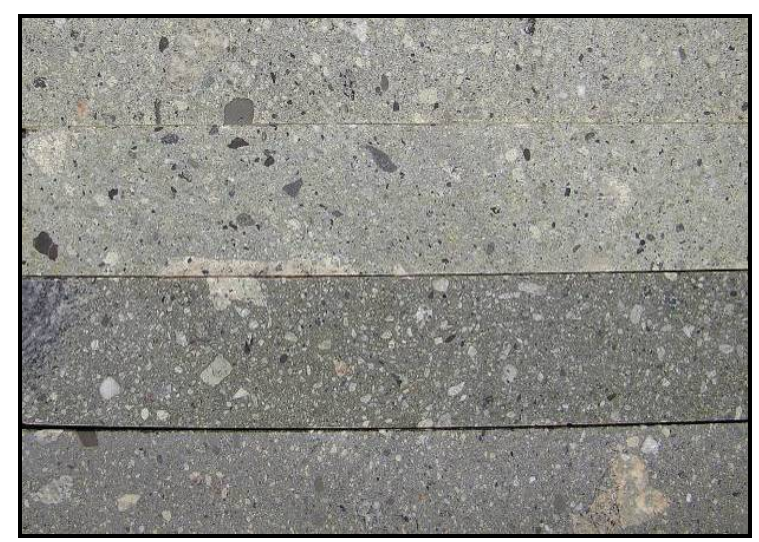

Figure 2: Photograph of drill core slabs of KIMB-1 (top two slabs) and KIMB-2 (bottom two slabs). Although both rock types are generally similar with respect to juvenile kimberlite components, KIMB-2 is characterised by a high proportion of mud in the interclast matrix and is thus brown in colour.

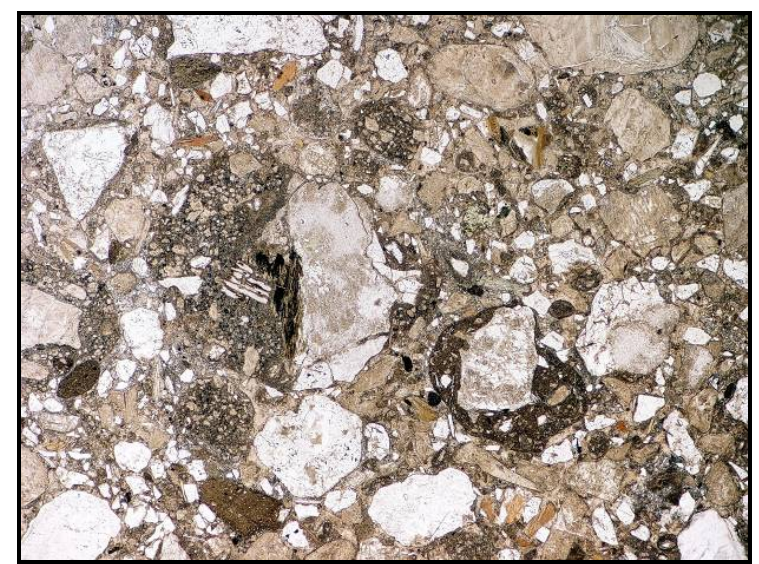

Figure 3: Photomicrograph of KIMB-1, highlighting angular to rounded, altered olivine, granitic xenocrysts, juvenile clasts, and clasts of RVK, set in a serpentine and ash matrix.

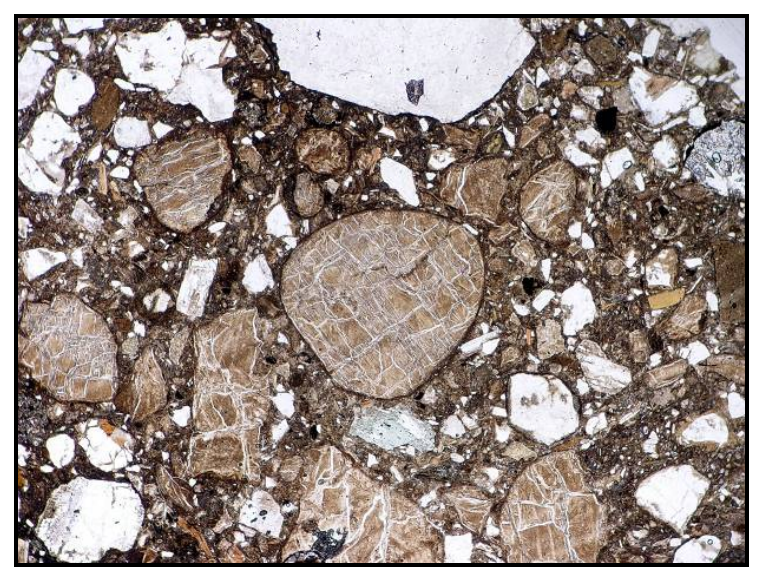

Figure 4: Photomicrograph of KIMB-2, highlighting common broken and unbroken, altered olivine macrocrysts, granitic xenocrysts, and less common juvenile clasts set in a mud and ash matrix.

\section{DO-18 Depositional Processes}

The processes responsible for infilling the DO-18 pipe are interpreted to be complex and to have involved several episodes of dominantly primary pyroclastic and dominantly sedimentary deposition. The PK domain (KIMB-1) is interpreted to have formed by collapse of an eruption column at a relatively early stage in the emplacement process. The presence of two distinct juvenile clast types within this domain suggests mixing of two different kimberlite phases during its formation, This may have occurred through incorporation of material from a previous eruption of DO-18 or from a nearby kimberlite volcano into the eruption column. The RVK domain (KIMB-2) is locally mixed with the KIMB-1 PK and is interpreted to have been deposited primarily by resedimentation of extra-crater deposits following cessation of the eruption. However, the boundary between the KIMB-1 and KIMB-2 domains (Figures 5-6) is gradational and inter-fingering, indicating that resedimentation processes were active during pyroclastic deposition. The inter-fingering mudrich KIMB-2 intervals likely represent brief lulls or episodes of lowered eruption intensity, and are 
concentrated near the pipe margins. Complex and highly altered volcaniclastic kimberlite also locally overlies the main DO-18 pipe fill and likely represents late-stage resedimentation into the upper part of the kimberlite pipe.

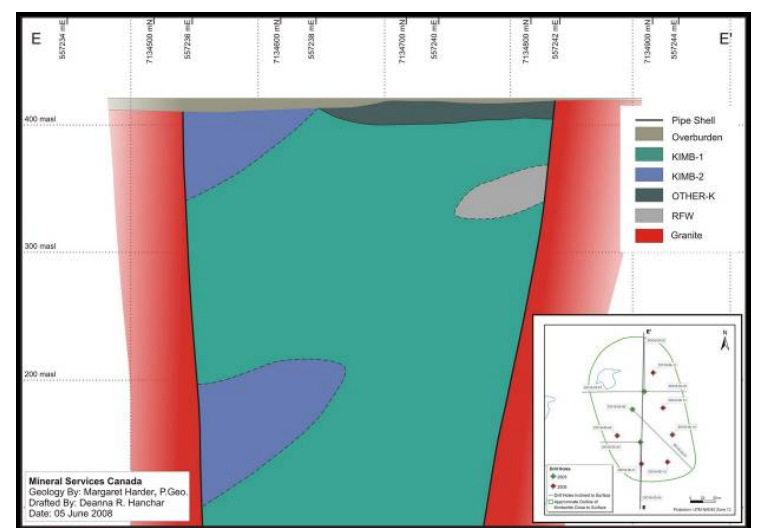

Figure 5: North-South cross section of the DO-18 kimberlite showing KIMB-2 lenses (blue) in the southern part of the dominant KIMB-1 pipe fill (green). Variable RVK (grey and dark green) is present locally in the upper northern part of the pipe.

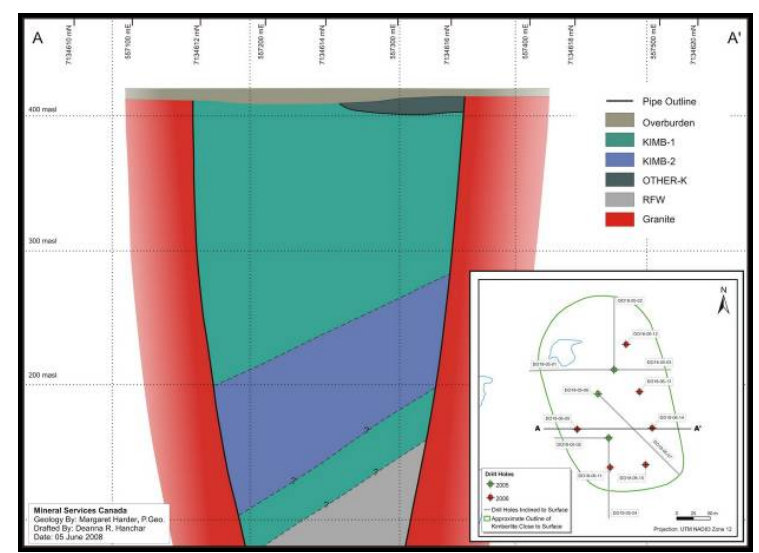

Figure 6: East-West cross section across the southern part of the pipe showing inter-bedded KIMB-1 (green) and KIMB-2 (grey); complex granite and mud-rich kimberlite is present at depth (grey).

\section{Discussion}

Although the DO-18 kimberlite is similar to the classic Lac de Gras-type or Class-3 kimberlites in terms of pipe morphology and the main pipe infill, it is distinguished from most of those localities by the high proportion of accessory country-rock granite and locally developed strongly brecciated / pulverized country-rock contact zones at the pipe margins. These features provide insights into the eruption and depositional mechanisms involved in the formation and infill of this kimberlite pipe. Furthermore, the volcaniclastic kimberlite characteristic of DO-18 is distinctly different from that of DO-27, despite the close proximity of these bodies and comparable country-rock setting. This suggests that contrasting eruption and deposition mechanisms were involved in the emplacement of these two bodies. The DO-27 pipe fill comprises a highly fragmental kimberlite in which nearly all olivine grains are broken, indicative of a high-energy volcanic eruption. Furthermore, the eruption column must have been sustained for a significant period of time, allowing the majority of kimberlitic ash size particles smaller than $1 \mathrm{~mm}$ and nearly all granitic country-rock material to be dispersed away from the vent (see Harder et al., this volume). Marginal breccias are only locally present near the DO-27 body, and volcaniclastic deposits representing early stages of the eruption are also preserved only locally along the margins of the body. This suggests the DO-27 vent was explosively cleared and remained open to the surface for a considerable period of time prior to the main infilling event. The DO-18 kimberlite is similarly highly fragmental and characterised by juvenile clasts, or remnants of the unfragmented magma, that are relatively uncommon $(<5 \%)$ and generally small $(<2 \mathrm{~mm})$. However, the presence of marginal breccias, significant proportions of accessory country-rock material, and common unbroken olivine grains and kimberlitic ash distinguish the DO-18 kimberlite from DO-27. The energy of volcanic explosions producing and infilling the DO-18 pipe was insufficient to effectively break all olivine grains. The eruption column was likely not high enough or sustained for long enough to allow for dispersal of the country-rock granitic material and kimberlitic ash significant distances from the vent. The marginal breccias likely represent the remnant products of early pipe formation and excavation processes that did not efficiently ream out the pipe prior to infilling.

\section{Conclusion}

The DO-18 pipe fill is comprised predominantly of pyroclastic kimberlite; resedimented kimberlite is locally common, primarily along the southern pipe margin. This kimberlite is atypical of Lac de Gras kimberlites in terms of the high proportion of countryrock accessory granite and the common occurrence of marginal country rock breccias. The DO-18 pipe is interpreted to have been excavated and infilled by a relatively low-energy, short-lived eruption.

\section{References}

Sweet, A.R., Stasiuk, L.D., Nassichuk, W.W., Catuneanu, O., McIntyre, D.J., 1998. Paleontology and diamonds: geological environments associated with kimberlite emplacement, Lac de Gras, Northwest Territories, Canada. In: Extended Abstracts of the VIIIth International Kimberlite Conference, Victoria. Abstract FLA_0086.

Doyle, B.J., Kivi, K., Scott Smith, B.H., 1999. The Tli Kwi Cho (DO27 and DO18) Diamondiferous Kimberlite Complex, Northwest Territories, Canada. In: Proceedings of the VIIth International Kimberlite Conference, Cape Town. Vol 1, 194-204.

Harder, M., Hetman, C.M., Scott Smith, B.H., Pell, J., Baumgartner, M.C., 2008. The evolution of geological models for the DO-27 kimberlite, NWT, Canada: implications for evaluation. This volume. 